\title{
POLÍTICA DE VALORIZAÇÃO E REMUNERAÇÃO DOS PROFESSORES DA REDE PÚBLICA MUNICIPAL DE RIO BRANCO: O PCCR EM QUESTÃO
}

\author{
Mark Clark Assen de Carvalho ${ }^{1}$ \\ Pelegrino Santos Verçosa ${ }^{2}$ \\ Jean Mauro de A. Morais $^{3}$
}

\section{CONSIDERAÇÕES INICIAIS: PLANO DE CARGOS, CARREIRA E REMUNERAÇÃO DO MAGISTÉRIO NO CONTEXTO DA LEGISLAÇÃO BRASILEIRA NAS ÚLTIMAS DÉCADAS}

O cenário das políticas educacionais no Brasil, nos últimos anos, tem passado por mudanças significativa dentre as quais se encontram a questão da valorização profissional docente mediante processos de revisão e/ou aprovação dos planos de cargos, carreira e remuneração dos profissionais do magistério público. Pode-se dizer que nesse percurso a valorização acaba por assumir certa centralidade no contexto das políticas públicas mais recentes.

Esse estudo busca compreender a dinâmica que envolve esse processo e, principalmente, aos aspectos que dizem respeito à composição da remuneração do magistério público, no Estado do Acre considerando as proposições expressas na legislação macro e seus desdobramentos nas políticas públicas voltadas para constituição do Plano de Cargos, Carreira e Remuneração (PCCR). Para o contexto no qual a pesquisa incide, o compromisso que se impõe é o de buscar identificar, descrever e analisar o conjunto dessas ações e seus efeitos sobre a valorização dos profissionais do magistério.

Dessa forma, as questões preliminares e que balizam as referências se reportam aos princípios da educação nacional no texto da Constituição Federal (CF) 1988, Art. 206, Inciso V:

V - valorização dos profissionais do ensino, garantido, na forma da lei, plano de carreira para o magistério público, com piso salarial profissional e ingresso

\footnotetext{
${ }^{1}$ Doutor em Educação pela Pontifícia Universidade Católica - PUC/SP. Professor Titular do Centro de Educação, Letras e Artes e do Programa de Pós-graduação em Educação da Universidade Federal do Acre.

${ }^{2}$ Doutor em Educação pela Universidade Federal do Paraná - UFPR. Professor do Centro de Educação Letras e Artes da Universidade Federal do Acre.

${ }^{3}$ Mestre em Educação pela Universidade Federal do Acre - UFAC. Professor da rede pública estadual de educação do Acre e Professor-Formador no Plano Nacional de Formação de Professores para a Educação Básica - PARFOR/UFAC
} 
exclusivamente por concurso público de provas e títulos, assegurado regime jurídico único para todas as instituições mantidas pela União;

[...] (BRASIL, 1988)

A partir das determinações da CF 1988, a demanda da valorização dos profissionais do ensino passou a configurar-se como um princípio importante que deveria ser levado a cabo pelo poder público considerando, dentre outros fatores, a necessidade de constituição do plano de carreira, a definição clara do piso salarial, a exclusividade de ingresso na carreira por meio da realização de concurso público de provas e títulos. Esses elementos são indicativos fundamentais para configurar uma política real de valorização do magistério público. Assim, concordamos com as proposições de Camargo et al (2009) para os quais os termos da CF implicaram em importantes desdobramentos para as políticas educacionais.

A Lei de Diretrizes e Bases da Educação Nacional (LDB), Lei n 9.394/1996, mantem a valorização do profissional da educação como um dos seus princípios, estabelecendo no Art.67 que os sistemas de ensino deverão estabelecer de forma prática esse processo. Esse mesmo artigo reitera o disposto na Constituição e define que o ingresso na carreira do magistério deva ser feito exclusivamente por concurso público de provas e títulos; piso salarial; licenciamento remunerado para aperfeiçoamento profissional; progressão funcional baseada na titulação ou habilitação, bem como por avaliação de desempenho; garantia de período reservado para estudos, planejamento e avaliação na carga horária de trabalho; além de condições adequadas de trabalho.

Por seu turno, o Art.70, Inciso I da referida Lei, estabeleceu como despesas de Manutenção e Desenvolvimento do Ensino, a remuneração e aperfeiçoamento do pessoal docente e demais profissionais da educação. Esta propositura se constituiu em aspecto importante na dinâmica de funcionamento das Políticas de Fundos da Educação Pública brasileira, considerando a dimensão do financiamento da educação básica que, por sua vez, deveria garantir os investimentos necessários para consolidação do ensino de qualidade.

Nesse particular a Emenda Constitucional no 14/1996 determinava que 60\% dos recursos da vinculação constitucional deveriam compor o Fundo de Desenvolvimento do Ensino Fundamental e Valorização do Magistério (FUNDEF), regulamentado pela Lei no 9.424/1996, que em seu Art. 9º determinava que após a sanção dessa lei deveriam ter sido construídos e aprovados os Planos de Cargos e Remuneração do Magistério, tomando por princípio a remuneração condigna dos 
profissionais do magistério do ensino fundamental; do incentivo ao trabalho na sala de aula e a melhoria da qualidade de ensino.

$\mathrm{Na}$ esteira deste movimento, a Emenda Constitucional no 53/2006 alterou o Art. 206 da CF 1988 estabelecendo a valorização dos profissionais da educação básica garantindo-lhes planos de carreira, piso salarial indicando para necessidade de definição de prazo para o cumprimento dessa norma. A Lei n 11.494/2007, que regulamentou o Fundo de Desenvolvimento da Educação Básica e Valorização dos Profissionais da Educação (FUNDEB) estabeleceu que:

Art. 22. Pelo menos $60 \%$ (sessenta por cento) dos recursos anuais totais dos Fundos serão destinados ao pagamento da remuneração dos profissionais do magistério da educação básica em efetivo exercício na rede pública.

Parágrafo único. Para os fins do disposto no caput deste artigo, considera-se:

I - remuneração: o total de pagamentos devidos aos profissionais do magistério da educação, em decorrência do efetivo exercício em cargo, emprego ou função, integrantes da estrutura, quadro ou tabela de servidores do Estado, Distrito Federal ou Município, conforme o caso, inclusive os encargos sociais incidentes;

II - profissionais do magistério da educação: docentes, profissionais que oferecem suporte pedagógico direto ao exercício da docência: direção ou administração escolar, planejamento, inspeção, supervisão, orientação educacional e coordenação pedagógica;

III - efetivo exercício: atuação efetiva no desempenho das atividades de magistério previstas no inciso II deste parágrafo associada à sua regular vinculação contratual, temporária ou estatutária, com o ente governamental que o remunera, não sendo descaracterizado por eventuais afastamentos temporários previstos em lei, com ônus para o empregador, que não impliquem rompimento da relação jurídica existente.

(BRASIL, 2007)

Diferentemente do FUNDEF que destinava esse percentual para os profissionais que atuavam no ensino fundamental regular, a Lei n ${ }^{\circ}$ 11.494/2007 manteve a subvinculação de 60\% dos recursos que compõem o FUNDEB para o pagamento dos profissionais do magistério da educação básica que estejam em efetivo exercício na educação básica pública. Além disso, se destaca a questão dos profissionais do magistério definida por esta mesma lei que passou a incorporar os profissionais que exercem funções não docentes como, por exemplo, as de administração, supervisão e coordenação pedagógica. 
Outro fundamento legal importante para os profissionais do magistério público brasileiro é a Lei $n^{\circ} 11.738 / 2008$ que institui o Piso Salarial Profissional Nacional (PSPN), a qual foi alvo de uma Ação Direta de Inconstitucionalidade, sendo necessária a ação e decisão do Supremo Tribunal Federal para equacionamento dos diferentes questionamentos surgidos em grande parte dos estados da federação.

No geral, o PSPN define o vencimento básico dos professores com formação em nível médio, na modalidade normal, para uma jornada de 40 horas semanais, sendo que nos casos de outras jornadas de trabalho o vencimento deverá ser proporcional à quantidade de horas trabalhadas. Entre as muitas disposições estabelecidas destacamos para finalizar que o valor do piso é atualizado anualmente, tomando por base o mesmo percentual de crescimento do valor aluno ano (BRASIL, 2008).

Sobre o conjunto dos dispositivos gerais da legislação educacional se destaca ainda as Resoluções do Conselho Nacional de Educação (CNE), da Câmara de Educação Básica (CEB) nº 03/1997 e 02/2009, que estabelecem diretrizes para construção dos planos de cargos, carreira e remuneração do magistério dos Estados, Distrito Federal e dos Municípios.

Sem discutir os detalhes dessas resoluções, ressalta-se, na sequência, alguns de seus aspectos dentre eles o fato de que a Resolução CNE/CEB n ${ }^{\circ}$ 03/1997 reitera o foco na remuneração do magistério do ensino fundamental, visto que a subvinvulação dos recursos do FUNDEF atendiam especificamente os profissionais que atuavam nessa etapa da educação básica. Já a Resolução CNE/CEB nº 02/2009 contempla todos os profissionais do magistério público, considerando toda a educação básica.

No Plano Nacional de Educação (PNE) a questão é tema recorrente considerando, por exemplo, o fato de que na Lei $\mathrm{n}^{\circ}$ 10.172/2001 havia, dentre outras determinações, a necessidade de se implantar os planos de cargos e carreira do magistério, como também de atualização dos existentes; a gradual inserção da jornada de tempo integral, bem como o estabelecimento de um percentual de $20 \%$ a $25 \%$ da carga horária de trabalho para hora atividade.

O atual PNE, consubstanciado na Lei n ${ }^{\circ} 13.005 / 2014$, é outro dispositivo legal importante para as análises pretendidas considerando o que está previsto nas seguintes metas.

Meta 16: formar, em nível de pós-graduação, 50\% (cinquenta por cento) dos professores da educação básica, até o último ano de vigência deste PNE, e garantir a todos (as) os (as) profissionais da educação básica formação continuada em sua área 
de atuação, considerando as necessidades, demandas e contextualizações dos sistemas de ensino.

Meta 17: valorizar os (as) profissionais do magistério das redes públicas de educação básica de forma a equiparar seu rendimento médio ao dos (as) demais profissionais com escolaridade equivalente, até o final do sexto ano de vigência deste PNE.

Meta 18: assegurar, no prazo de 2 (dois) anos, a existência de planos de Carreira para os (as) profissionais da educação básica e superior pública de todos os sistemas de ensino e, para o plano de Carreira dos (as) profissionais da educação básica pública, tomar como referência o piso salarial nacional profissional, definido em lei federal, nos termos do inciso VIII do art. 206 da Constituição Federal. (BRASIL, 2014)

Embora se esteja longe de uma avaliação das consequências na produção de políticas educacionais do novo PNE, ressalta-se que as mesmas não foram cumpridas anteriormente e que permanecem nos discursos e no horizonte da educação. Nesse sentido, a Meta 16 é um indicativo para valorização dos profissionais da educação básica, como também pode significar um componente importante na remuneração dos professores, visto que a pós graduação faz parte das categorias de composição. Caso seja cumprida a meta em questão teremos consequências não somente na remuneração do magistério, mais principalmente nas folhas de pagamento. Nesse aspecto é que se procura compreender como essa questão está disposta no plano de cargos, carreira e remuneração do magistério público de Rio Branco.

A Meta 17 é desafiadora, pois representa a tomada de inciativa em produzir políticas públicas para reverter o quadro de percas da remuneração do magistério público, especialmente quando comparado com profissionais de mesmo nível de formação.

No que se refere à Meta 18 o que pode inferir é a reincidência da necessidade de se constituir os PCCR do magistério. Esse é um indicador importante, pois nos últimos anos se nota a centralidade dessa política, porém o não cumprimento dessa demanda tem sido recorrente entre os entes federados.

No caso específico do município de Rio Branco, capital do Estado do Acre será apresentado, na segunda parte desse estudo, algumas dessas consequências, entre elas o fato de que em 1987 foi aprovado o Plano de Cargos, Salários, Benefícios e Vantagens do Magistério Acreano, antes mesmo da nova Constituição (ACRE, 1987). Apesar de ser específico da rede pública estadual, o PCS passou a funcionar como parâmetro que indexou a produção dos planos no âmbito dos municípios acreanos. 


\section{O PLANO DE CARGOS, CARREIRA E REMUNERAÇÃO DO MAGISTÉRIO PÚBLICO DO MUNICÍPIO DE RIO BRANCO: PRIMEIRAS ANÁLISES}

O atual Plano de Cargos, Carreira e Remuneração (PCCR) dos Servidores da Educação Pública do Município de Rio Branco é regulado pela Lei no 35, de 19 de dezembro de 2017. Essa legislação pode ser considerada como o primeiro documento voltado exclusivamente para atender as características dos profissionais da educação, pois anteriormente a matéria estava referenciada pela Lei n ${ }^{\circ}$ 1.892, de 03 de abril de 2012, que instituiu o Plano de Cargos, Carreira e Remuneração dos Servidores da Administração Pública Direta do Município de Rio Branco.

A esse respeito Dutra Jr (2000) esclarece que a depender da situação construída pelos entes federados a matéria do PCCR do magistério pode ser construído em legislação exclusiva ou juntamente com os demais servidores públicos. Portanto, a Lei $\mathrm{n}^{\mathrm{o}} 35 / 2017$ pode ser considerada o primeiro PCCR dos profissionais da educação de Rio Branco.

A anatomia do novo PCCR estabelece algumas definições como forma de organização da vida dos profissionais da educação. A primeira, é o próprio reconhecimento do PCCR como forma de desenvolvimento e valorização dos servidores da educação. (Cf. Art. $2^{\circ}$ ).

Dentre as muitas definições tratadas no documento destaca-se as definições de vencimento base, remuneração e carreira. O vencimento base é definido como "o valor correspondente ao nível do grupo ocupacional, acrescido do respectivo grau padrão"; remuneração entendida como "vencimento base, acrescido das parcelas permanentes pessoais ou inerentes ao cargo, na forma estabelecida em Lei”, enquanto que carreira é "a trajetória do servidor desde seu ingresso no cargo público até seu desligamento, regida por regras específicas de ingresso, desenvolvimento profissional e remuneração" (RIO BRANCO, 2017).

Ainda tratando das demarcações estabelecidas no PCCR (2017), especificamente sobre profissionais do magistério e funções do magistério, estabelece que:

XVI - são profissionais do magistério, nos termos da Lei de Diretrizes e Bases da Educação - LDB, n 9.394, de 20 de dezembro de 1996 e da Lei do Piso Nacional do Magistério, $\mathrm{n}^{\mathrm{o}} 11.738$, de 16 de julho de 2008, os que desempenham as atividades de docência ou de suporte pedagógico à docência, isto é, direção ou administração, planejamento, inspeção, supervisão, orientação e coordenação educacional, exercidas no âmbito das unidades escolares de educação básica, em suas diversas etapas e modalidades, com a formação mínima determinada na legislação citada neste inciso; 
XVII - são consideradas funções do magistério, além do exercício da docência em sala de aula, as funções de direção, coordenação e assessoramento pedagógico, quando exercidas por professores de carreira, em estabelecimentos de educação básica, prevista na Lei de Diretrizes e Bases da Educação Nacional, excluindo os especialistas em educação e o exercício de funções meramente administrativas em que não seja obrigatória a participação do magistério (RIO BRANCO, 2017, p. 3-4).

A legislação municipal praticamente repete o que determina o ordenamento nacional. Porém, ao texto do PCCR acrescenta-se a figura do especialista em educação e dos profissionais que trabalham com atividades administrativas. Nesse mesma perspectiva, estabelece dois quadros de profissionais: profissionais efetivos e profissionais suplementares, sendo que esses últimos, compõem um quadro em extinção de servidores.

O quadro de profissionais da educação pública de Rio Branco, estabelecido no Art. $5^{\circ}$, é composto por: Professor, Professor Coordenador, Professor da Educação Infantil, Professor da Educação Especial, Assistente de Creche, Assistente Educacional, Assistente Escolar, Cuidador Pessoal, Inspetor de Alunos, Merendeira, Técnico em Alimentação Escolar, Técnico de Multimeios Didáticos, Técnico de Secretária Escolar, Técnico de Infraestrutura Material e Ambiental, e Tradutor e Intérprete da Língua Brasileira de Sinais (LIBRAS).

Os professores atuam essencialmente com a educação infantil, os anos iniciais do ensino fundamental, com a educação especial e como coordenador pedagógico. Além disso, podem exercer a função de diretor das unidades escolares. A jornada de trabalho dos profissionais do magistério poderá ser de 25 (vinte e cinco) horas e 40 (quarenta) horas semanais, sendo distribuídas em hora aula e hora de planejamento. Neste último caso, a hora de planejamento é o que no Piso Salarial Profissional Nacional (PSPN) se denomina como hora atividade, que é estabelecida em 1/3 da jornada de trabalho.

Os professores em regência de sala de aula, devem cumprir a seguinte jornada: pré-escola, ensino fundamental e ensino médio cumprem 20 (vinte) horas em sala de aula e 5 (cinco) horas de planejamento; os profissionais que atuam em creche com 25 (vinte e cinco) ou 40 (quarenta) horas semanais destinam sua jornada exclusivamente para regência, incluindo a hora de planejamento. De modo geral, o 1/3 da jornada de trabalho destinada para hora atividade não é cumprido na sua plenitude.

No regime suplementar, os profissionais do magistério podem ser convocados para prestação de serviço de no máximo 15 (quinze) horas semanais. Essa possibilidade se aplica essencialmente aos professores que possuem jornada de trabalho de 25 (vinte e cinco) horas, assim 
sendo, o pagamento deve ser calculado de forma proporcional as horas suplementares, considerando como padrão o vencimento base.

Outra possibilidade que se aplica é o regime de dedicação exclusiva para o qual o servidor deverá ter um único vínculo empregatício e exercer suas atividades em regime de 40 (quarenta) horas semanais, em dois turnos de trabalho. Além disso, esse profissional terá direito ao Adicional de Dedicação Exclusiva (ADE) que corresponde a 100\%, sobre o vencimento base.

No Art. 16 define as exigências mínimas em termos de formação mínima para atuação nas etapas da educação básica cuja responsabilidade da oferta é do poder público municipal: nível superior em curso de licenciatura plena em observância ao que está definido na LDB 9394/1996.

Assim sendo se explicita que: $\mathrm{O} \S 1^{\circ}$ define ainda que para trabalhar na Educação Infantil e nos cinco primeiros anos do Ensino Fundamental, o docente deverá ter formação em Pedagogia. Os professores com formação em áreas especificas ou que possuam complementação pedagógica, em conformidade com a legislação, poderão atuar nos anos finais do ensino fundamental. Ainda sobre esse aspecto, o $\S 3^{\circ}$ garante que professores com formação em nível médio, que estejam em atividade na rede municipal, também possam atuar na Educação Infantil e nos Anos Iniciais do Ensino Fundamental, respeitando o que estabelece o Art. 62, da LDB 9.394/1996 (BRASIL, 1996).

A função de Professor Coordenador foi criada pela Lei $n^{0}$ 1.892/2012 e resguardada no atual PCCR (2017), sendo definindo que a formação mínima exigida é em nível superior com Licenciatura em Pedagogia ou especialização na área de educação. Além disso é exigido ainda experiência mínima de 02 (dois) anos de efetivo exercício no magistério e aprovação em processo de certificação. Excepcionalmente, nas escolas rurais, em caso de carência de pessoal com a habilitação requerida, admite-se profissionais com formação em magistério de nível médio.

Em termos de desenvolvimento na carreira, o grupo dos profissionais do magistério é composto por VI (seis) níveis e 9 graus (referências/letras). O regime de progressão funcional do magistério municipal por ser entendido como conjunto de medidas que possibilitam o avanço de um grau (referência/letra) para o outro imediatamente superior, ocorre em sentido horizontal da tabela salarial. Esse processo se dá automaticamente a cada 03 (três) anos de efetivo serviço público municipal, tendo um acréscimo de uma referência/letra para outra de 6,051 sobre o vencimento base (RIO BRANCO, 2017).

A propósito, o Art. 10 define que a promoção dos profissionais do magistério público de Rio Branco é a passagem do servidor de um nível para outro no mesmo grupo, obedecendo aos seguintes critérios: 
I - permanência de no mínimo de 04 (quatro) anos no nível que se encontra;

II - comprovar a conclusão de:

d) no mínimo um dos títulos de especialização, mestrado ou doutorado, reconhecidos pelo Ministério da Educação e vinculados a sua área de atuação, para os servidores da educação pública municipal do grupo 4.

III - não ter sofrido punição disciplinar, após processo de sindicância ou processo administrativo disciplinar, no período dos 04 (quatro) anos necessários à permanência no nível que se encontra;

IV - comprovar assiduidade (RIO BRANCO, 2017).

Os critérios definidos como condições essenciais para promoção dos professores, articula a permanência no nível com aspectos disciplinares, além da possibilidade de ter a promoção garantida pela obtenção de títulos de pós-graduação.

De outro modo, a promoção pode ser retardada a considerar que a sanção disciplinar impõe ao servido uma espécie de suspensão de quatro anos, ou seja, somente após esse período é que o profissional poderá ter direito a promoção. Está prevista uma punição que estabelece retardo de 1(um) mês para cada falta injustificada dentro do período necessário à permanência no nível (4 anos). Prescreve ainda que o servidor não poderá exceder 8 (oito) faltas injustificadas no período de 04 (quatro) anos sob pena de reiniciar nova contagem com vistas à promoção a partir do primeiro dia útil, contado a partir da oitava falta injustificada. Cumpridos esses requisitos, o servidor terá, após a promoção, um acréscimo pecuniário de $4 \%$ (quatro por cento).

Os professores em efetivo exercício de sala de aula e o Professor Coordenador podem receber o adicional de pós-graduação, que é calculado tomando por referência o vencimento base, nos seguintes percentuais: 10\% (dez por cento) para especialização com carga horária mínima de 360 (trezentas e sessenta horas); $15 \%$ (quinze por cento) para mestrado e 20\% (vinte por cento) para doutorado. Esses percentuais podem ser cumulativos, podendo chegar no máximo a $25 \%$ (RIO BRANCO, 2017).

Além dos adicionais de titulação citados, os professores da rede municipal de Rio Branco, quando convocados para prestar serviço em regime suplementar de, no máximo, 15 horas farão jus ao pagamento de uma complementação salarial calculada proporcionalmente aos seus vencimentos base. Já aqueles que possuem apenas um vínculo empregatício, poderão ser convocados para prestar serviços em regime de dedicação exclusiva (DE) ampliando sua jornada para 40 horas semanal, em 
dois turnos de trabalho e perfazendo direito a um Adicional de Dedicação Exclusiva (ADE), correspondente a $100 \%$ (cem por cento), calculado sobre seu vencimento base.

Por fim, os profissionais da educação poderão ainda converter os períodos de licença-prêmio existentes em pecúnia, desde que devidamente comprovado sua existência por Certidão emitida pela Secretaria Municipal de Administração e Gestão de Pessoas (SEAD) e preenchido processo específico para tal.

Para os professores lotados em escolas de difícil acesso, especialmente aquelas que estão situadas fora do perímetro urbano, em zonas rurais, classificadas através de Decreto Municipal, será atribuído um adicional que varia de $15 \%$ a $30 \%$ (por cento), a depender da situação.

No tocante as férias, o Plano estabelece para o Professor regente de classe ou professor coordenador terá direito a um período correspondente de 45 (quarenta e cinco) dias, o que implica no pagamento de abono proporcional de $30 \%$ conforme prevê a legislação trabalhista brasileira.

Em relação à remuneração dos profissionais nomeados nas funções de diretor de escola, coordenador administrativo e coordenador geral de creche, o Plano define no anexo IX da Lei $\mathrm{n}^{\circ}$ 1.892/2012 a tabela salarial expressa nos seguintes valores:

Tabela I:

Remuneração de Diretores e Coordenadores de Creches

\begin{tabular}{|c|c|c|c|c|}
\hline Escola & $\mathbf{N}^{\mathbf{0}}$ de alunos & $\begin{array}{c}\text { Remuneração } \\
\text { Diretor }\end{array}$ & $\begin{array}{c}\text { Diretor com dois } \\
\text { contratos } \\
\text { Adicional }\end{array}$ & $\begin{array}{c}\text { Coordenador } \\
\text { Administrativo } \\
\text { Adicional }\end{array}$ \\
\hline Tipo B & 101 a 600 & $4.535,00$ & $1.375,00$ & 900,00 \\
\hline Tipo C & 601 a 1200 & $4.915,50$ & $1.485,00$ & $1.012,00$ \\
\hline
\end{tabular}

Fonte: Lei Complementar $n^{\circ} 35 / 2017$

Além da tabela que define a tipificação das escolas de acordo com o número de alunos e a remuneração dos diretores e coordenadores de creches da Rede Municipal de Ensino de Rio Branco, a Lei $\mathrm{n}^{\mathrm{o}}$ 1.892/2012 define algumas regras que precisam ser observadas para efeito de composição da remuneração desses profissionais. O diretor de escola com dois contratos, por exemplo, receberá diferença entre o somatório dos vencimentos da carreira, referente aos seus cargos (acumulados legalmente) e um adicional ( $\mathrm{R} \$ 1.375,00$ para escola tipo B e $\mathrm{R} \$ 1.485,00$ para escola tipo C). Os coordenadores gerais de creche têm direito a perceber remuneração igual aos diretores das escolas do tipo B.

Por fim, o Plano garante, aos professores do quadro da Secretaria Municipal de Educação de Rio Branco em efetiva regência, diretores e coordenadores administrativos e pedagógicos, Prêmio 
Anual de Valorização e Desenvolvimento Profissional-VDP, cujos critérios são definidos em decreto do Poder Executivo.

Tabela II:

Prêmio pela elevação da qualidade da aprendizagem - PEQ

\begin{tabular}{|c|c|}
\hline Profissionais & Valores- PEQ \\
\hline Profissionais do Magistério & $\mathrm{R} \$ 1.672,33$ \\
\hline Servidores Administrativos & $\mathrm{R} \$ 724,00$ \\
\hline
\end{tabular}

Fonte: Lei no 35/2017.

Caso cumpram com as normas estabelecidas que articulam participação nas atividades de planejamento, formação, construção do projeto político pedagógico da escola e de aspectos relacionados ao desempenho dos alunos, os profissionais da educação da rede municipal de Rio Branco podem somar aos seus vencimentos os valores correspondentes ao Prêmio pela Elevação da Qualidade da Aprendizagem (PEQ).

No geral, o PCCR da rede municipal de Rio Branco articula direitos dos trabalhadores da educação com elementos da cultura do desempenho, aspecto bastante evidente no curso das políticas de educação implementadas no Estado do Acre nas duas últimas décadas. Entretanto, dada a amplitude da questão essas particularidades serão objeto de análises futuras advindas de outras pesquisas que se voltarão para analisar os efeitos da política de bonificação e da cultura do desempenho sobre a organização do trabalho pedagógico das escolas públicas da rede municipal de ensino e sobre a organização do trabalho docente.

\section{CONSIDERAÇÕES FINAIS:}

A partir da apresentação de questões iniciais dos estudos desenvolvidos sobre a formulação e implantação do PCCR dos profissionais da educação do município de Rio Branco foi-nos possível chegarmos a algumas considerações mesmo que de natureza bastante preliminar.

Dentre estas uma primeira a ser destacada repousa no fato de que foi somente a partir da Lei n 35/2017 que efetivamente os profissionais da educação do Município de Rio Branco passaram a ter um PCCR exclusivo. Assim, o reconhecimento do poder público municipal acerca da importância de se ter o PCCR para os profissionais da educação parece-nos fundamental para legitimar e efetivar direitos, condição esta que corrobora com as premissas da legislação nacional que reiteram a necessidade de construção dos planos de cargo, carreira e remuneração, bem como de iniciativas tomadas no âmbito do governo municipal que passam, inclusive, pela construção do estatuto dos servidores municipais ao atual PCCR dos servidores da educação.

Relativamente ao vencimento base e a remuneração dos profissionais da educação pública da rede municipal de ensino de Rio Branco, ficou evidente que é necessário procurar compreender 
como funciona a dinâmica de determinação de ambas, pois para além das regras estabelecidas no PCCR, os possíveis ganhos salariais podem refletirem uma concepção de organização do trabalho escolar cuja lógica se inspira em princípios gerencialistas, de performance e desempenho a julgar que as gratificações e os abonos resultam do exercício de algumas funções, como, por exemplo, as de direção, de coordenação e de atuação que devem incidir muito diretamente sobre os resultados escolares.

No que se refere à progressão vertical na carreira os professores são valorizados de forma mais intensa quando da realização de cursos de pós-graduação lato sensu: especialização em detrimento da pós-graduação stricto sensu: mestrado e o doutorado. Um razão possível pode estar no fato de que no estado do Acre a possibilidade de acesso à pós-graduação sejam escassas comparativamente com outras realidades do pais ou mesmo em função da compreensão de que os profissionais da educação com maior titulação acadêmica dirigir-se-ão à educação superior. A progressão horizontal é garantida aos profissionais com a ressalva de que para ocorrer os servidores não devem possuir sanções administrativas.

Os professores cumprem uma jornada de vinte e cinco horas semanais das quais cinco horas são destinadas como hora atividade considerando essencialmente os que se encontram em regência de sala de aula. Cabe ressaltar ainda que o pagamento da Prêmio pela Elevação da Qualidade da Aprendizagem (PEQ) funciona como uma espécie de política de bonificação do magistério considerando as disposições constantes na estrutura do PCCR, os processos de valorização, organização e execução das atividades escolares, além das novas dinâmicas que passam a configurar o trabalho pedagógico nas escolas da rede pública municipal de Rio Branco.

Por fim, considerando a nova ambiência que passa a ser constituída com a vigência da Lei $\mathrm{n}^{\circ}$ 35/2017 impõe-se a necessidade de ampliar estudos e pesquisas que possam efetivamente contribuir para uma melhor explicitação de seus efeitos sobre a própria dinâmica de organização rede municipal de ensino de Rio Branco e em que medida estas novas determinações alteram tanto o trabalho pedagógico escolar quanto o trabalho docente em tempos de políticas de regulação e bonificação e da cultura do desempenho revestidas em um discurso de valorização do magistério. 


\section{REFERÊNCIAS:}

ACRE, Lei n ${ }^{\circ} 35 / 2017$. DOE $n^{\circ}$. 12.206, de 22 de dezembro de 2017.

ALVES, Thiago, PINTO, José Marcelino de Rezende. Remuneração e características do trabalho docente no Brasil: um aporte. Cadernos de Pesquisa, vol. 41, n. 143,2011. Disponível em http://www.scielo.br/pdf/cp/v41n143/a14v41n143.pdf. Acesso: 09 abr 12.

ARELARO, Lisete Regina. Fundef: uma avaliação preliminar dos dez anos de sua implantação. In: $30^{\mathrm{a}}$ Reunião da ANPED, 2007.

BRASIL, Constituição da República Federativa do Brasil. Disponível em: www.planalto.gov.br acesso em: 11 de julho de 2013.

, Emenda Constitucional no 14. Disponível em: www.planalto.gov.br acesso em: 06 de janeiro de 2012.

Lei n⿳ 9.424, de 24 de dezembro de 1996. Dispõe sobre o Fundo de Manutenção e Desenvolvimento do Ensino Fundamental e Valorização do Magistério. Disponível em: www.planalto.gov.br acesso em: 06 de fevereiro de 2012.

, Lei no 9.394, de 20 de dezembro de 1996. Estabelece as diretrizes e bases da educação nacional. Disponível em: www.planalto.gov.br acesso em: 11 de julho de 2013.

Lei $\mathbf{n}^{\circ}$ 10.172, de 09 de janeiro de 2001. Aprova o Plano Nacional de Educação e dá outras providências. Disponível em: www.planalto.gov.br acesso em: 06 de fevereiro de 2012.

2012.

Emenda Constitucional no 53/2006. Disponível em: www.planalto.gov.br acesso em: 06 de fevereiro de

Lei $\mathbf{n}^{\circ}$ 11.494, de junho de 2007. Regulamenta o Fundo de Manutenção e Desenvolvimento da Educação Básica e Valorização dos Profissionais da Educação. Disponível em: www.planalto.gov.br acesso em: 06 de fevereiro de 2012.

CAMARGO, R.B.; GOUVEIA, A.B.; GIL, J.; MINHOTO, M.A.P.. Financiamento da educação e remuneração docente: um começo de conversa em tempos de piso salarial. Revista Brasileira de Política e Administração da Educação, Porto Alegre, v. 25, n. 2, p. 341-363, maio/ago. 2009.

GOUVEIA, A.B; SOUZA, A.R. Os trabalhadores docentes da educação básica em uma leitura do possível das políticas educacionais. Archivos Analíticos de Políticas Educativas. vol.19, jan,2011.

PINTO, J.M.R. Financiamento da educação no Brasil: um balanço do governo FHC. Educação \& Sociedade. vol. 23. n. 80, p.108-135, set.2002.

. A política recente de fundos para o financiamento da educação e seus efeitos no pacto federativo. Educação \& Sociedade. vol. 28. n. 100 - Especial, p.877-897, out.2007.

. A divisão de responsabilidades pelo ensino no Brasil e o impacto das mudanças recentes na legislação.

Paidéia, FFCLRP-USP, Ribeirão Preto, Fev./Ago., 1996.

VALENTE, Ivan; ROMANO, Roberto. PNE: Plano Nacional de Educação ou Carta de Intenção? Educação \& Sociedade. vol. 23. n. 80, setembro/2002, p. 96-107.

VIEIRA, Sofia Lerche. Poder local e educação no Brasil: dimensões e tensões. Revista Brasileira de Política e Administração da Educação. Porto Alegre/RGS, v.27, n.1, p. 123-133. 


\section{POLÍTICA DE VALORIZAÇÃO E REMUNERAÇÃO DOS PROFESSORES DA REDE PÚBLICA MUNICIPA̧L DE RIO BRANCO: O PCCR EM QUESTÃO}

\section{RESUMO:}

O presente trabalho tem como foco de análise a questão da valorização do magistério e objetiva analisar a remuneração dos profissionais da educação do quadro de magistério da rede pública municipal de Rio Branco. O texto se organiza a partir de pesquisa empírica e revisão de literatura que procura sistematizar o arcabouço legal que define as diretrizes gerais a serem observadas por Estados e Municípios no que se refere propriamente à definição de uma política de valorização do magistério com destaque para Constituição Federal de1988, a LDB 9.394/1996, a Emenda Constitucional no 14/1996, a Lei Lei no 9.424/1996 do Fundo de Desenvolvimento do Ensino Fundamental e Valorização do Magistério (FUNDEF), a EC no 53/2006 que alterou o Art. 206 da CF 1988, a Lei no 11.494/2007 que regulamenta o Fundo de Desenvolvimento da Educação Básica e Valorização dos Profissionais da Educação (FUNDEB) e a Lei no 11.738/2008 que institui o Piso Salarial Profissional Nacional (PSPN). No contexto em que a análise está circunscrita toma-se como base de referência e análise a Lei no 35/2017 que instituiu o PCCR do Município de Rio Branco de cuja análise se indica que o vencimento base e a remuneração dos profissionais da educação muito mais do que refletirem ganhos salariais estão pautados por um política de bônus de lógica e princípios gerencialista, de performance e desempenho dos profissionais da educação.

Palavras-Chave: política de valorização do magistério; remuneração e carreira docente; plano de cargo, carreira e remuneração

\section{POLICY OF VALORIZATION AND REMUNERATION OF THE TEACHERS OF THE MUNICIPAL PUBLIC NETWORK OF RIO BRANCO: THE PCCR IN QUESTION}

\section{ABSTRACT:}

The present study focuses on the question of the valorization of teaching and aims to analyze the remuneration of education professionals in the teaching staff of the municipal public network of Rio Branco. The text is organized from an empirical research and literature review that seeks to systematize the legal framework that defines the general guidelines to be observed by States and Municipalities in what properly refers to the definition of a valorization policy of the teaching profession with emphasis on Federal Constitution 1988, LDB 9.394 / 1996, Constitutional Amendment No. 14/1996, Law No. 9.424 / 1996 of the Fund for the Development of Elementary Education and Valorization of the Magisterium (FUNDEF), EC No. 53/2006, which amended Art. 206 of CF 1988, Law No. 11,494 / 2007, which regulates the Fund for the Development of Basic Education and Valorization of Education Professionals (FUNDEB) and Law No. 11.738 / 2008 establishing the National Professional Salary Floor (PSPN). In the context in which the analysis is limited, it is based on reference and analysis Law No. 35/2017 that established the PCCR of the Municipality of Rio Branco, whose analysis indicates that the basic salary and the remuneration of education professionals much more of which reflect salary gains are based on a logic bonus policy and managerial principles, performance and performance of education professionals.

Key words: teaching valorization policy; remuneration and teaching career; job title, career and remuneration plan

\section{POLÍTICA DE VALORIZACIÓN Y REMUNERACIÓN DE LOS PROFESORES DE LA RED PÚBLICA MUNICIPAL DE RÍO BLANCO: EL PCCR EN CUESTIÓN}

\section{RESUMEN:}

El presente trabajo tiene como foco de análisis la cuestión de la valorización del magisterio y objetiva analizar la remuneración de los profesionales de la educación del cuadro de magisterio de la red pública municipal de 
Rio Branco. El texto se organiza a partir de investigación empírica y revisión de literatura que busca sistematizar el marco legal que define las directrices generales a ser observadas por Estados y Municipios en lo que se refiere propiamente a la definición de una política de valorización del magisterio con destaque para la Constitución Federal de acuerdo con lo establecido en la Ley Orgánica 15/1999, en el marco de la Ley Orgánica del Poder Legislativo, de la CF 1988, la Ley no 11.494 / 2007 que regula el Fondo de Desarrollo de la Educación Básica y la valorización de los Profesionales de la Educación (FUNDEB) y la Ley no 11.738 / 2008 que establece el Piso Salarial Profesional Nacional (PSPN). En el contexto en que el análisis está circunscrito se toma como base de referencia y análisis la Ley no 35/2017 que instituyó el PCCR del Municipio de Rio Branco de cuyo análisis se indica que el vencimiento base y la remuneración de los profesionales de la educación mucho más de lo que reflejan ganancias salariales están pautados por una política de bonos de lógica y principios gerencialistas, de desempeño y desempeño de los profesionales de la educación.

Palabras clave: política de valorización del magisterio; remuneración y carrera docente; plan de cargo, carrera y remuneración 